\title{
A Study of Physical Activity Behaviour during the COVID-19 Pandemic
}

\author{
Sunita Sijwali*, Arunima Chauhan
}

\section{Sunita Sijwali*, Arunima Chauhan}

Department of Adult and Continuing Education and Extension, Jamia Millia Islamia, New Delhi, INDIA.

\section{Correspondence}

Sunita Sijwali

Scholar, Department of Adult and

Continuing Education and Extension, Jamia Millia Islamia, New Delhi-110025, INDIA.

Phone no: +91 8745046401

Email: sunitasijwali16@gmail.com

\section{History}

- Submission Date: 28-05-2021

- Revised Date: 10-06-2021

- Accepted Date: 12-07-2021

DOI : 10.5530/ijmedph.2021.4.37

Article Available online

http://www.jimedph.org/v11/i4

\section{Copyright}

(C) 2021 Phcog.Net. This is an openaccess article distributed under the terms of the Creative Commons Attribution 4.0 International license.

\begin{abstract}
Background:The COVID-19 restrictions curtailed various physical activities whose effects are unfortunate because daily exercise may help combat the disease by boosting our immune systems and counteracting some of the co-morbidities that make us more susceptible to severe COVID-19 illness. Objectives: To study the physical activity behaviour, levels and its relationship with personal variables during COVID-19 lockdown, and to explore the differences between the inactive and active group respondents in terms of physical activity preferences, motivating and restricting factors. Materials and Methods: Cross sectional descriptive online survey (Google forms) design was used and snowball sampling method was used to reach the respondents. Questionnaire consisted of four parts; 1) Demographics, 2) Occupation, Screen and Sleep behaviour, 3) Physical Activity behaviour, 4) Preferred physical activities, restricting and motivating factors to do any physical activity. To study the TPA OPA, MV-LTPA and HHPA were considered. Results and Discussion: A total of 400 respondents (male 56.2, female $43.2 \%)$ ) were eligible for the analysis, majority (93.6\%) of them were young adults (18-38) involved in sedentary to light occupation (95.3\%). Sedentary behavior in occupation was doubled $(80 \%)$ as compared to pre-COVID situation (42.5\%). Majority of the respondents reported an increase in screen and sleep time. On calculating TPA 33\% of the respondents were found in each group; inactive, active and very active. Majority of them were performing pa for $<150 \mathrm{~m} / \mathrm{w}$ in each domain i.e. OPA, MV-LTPA and HHPA. Significant difference was found between male and female, of all the three domains, in their physical activity group whereas no significant difference was found in their TPA group. Significant association was found between physical activity groups in terms of considering physical activity benefits, change in post COVID physical activity, and their self reported type of physical activity. Significant association was found between male and female respondents in terms of their BMI and perceived Body weight whereas no association was found between physical activity groups in terms of their BMI and body weight perception. Family/friends and health benefits were the most motivating factors for the majority of respondents whereas social distancing norms and lack of motivation were reported as restricting factors in doing physical activity. Conclusion: It can be concluded that physical activity among people was low even before the COVID-19 pandemic, this pandemic acted as a catalyst in promoting sedentary behavior.
\end{abstract}

Key words: Physical activity, Physical health, COVID-19.

\section{INTRODUCTION}

We are living in an unprecedented difficult time created by the COVID-19 pandemic throughout the world. The virus, which originated as an unexplained case of pneumonia in Wuhan China, was officially designated as COVID-19 by the World Health Organization. ${ }^{1}$ The highly contagious nature of the virus forced the governments of most of the countries to take extreme steps of announcing complete lockdown with different levels of restrictions. The lockdown brought India to a standstill as people were asked not to step out from their homes, all the transport services rail, road and air, were suspended, educational institutions, places of recreation (swimming pools, gymnasiums, theatres, entertainment parks, bars, auditoriums and assembly halls) and gatherings of any kind were totally prohibited from March $25^{\text {th }}$ 2020 to $14^{\text {th }}$ April 2020 which was further extended till $3^{\text {rd }}$ May 2020. Only essential services like Banks, grocery, medical, media, telecommunication, etc. were permitted. Later on it was extended in phases with certain relaxations in every successive phase. ${ }^{2}$ The total lockdown from March $25^{\text {th }}$ to $3^{\text {rd }}$ May, 2020 posed serious challenges of survival to many and issues of mental and physical health to almost everyone. Although lockdown 2.0 and 3.0 gave some relaxations but till $31^{\text {st }}$ May no significant change was seen in the mobility of people. ${ }^{3}$ The public health recommendations (i.e., stay-at-home orders, closures of parks, gymnasiums, and fitness centres etc.) to prevent SARS-CoV-2 spread have the potential to 
reduce daily physical activity (PA). These recommendations are unfortunate because daily exercise may help combat the disease by boosting our immune systems and counteracting some of the co-morbidities like obesity, diabetes, hypertension, and serious heart conditions that make us more susceptible to severe COVID-19 illness. As this virus strain is novel to the human immune system, we are dependent on aspects of our innate immunity to deal with the initial infection. ${ }^{4}$ Till date, no data is available whether the level of physical fitness affects the progress of SARS-CoV-2 infections. However, it is well documented that regular exercise induced-adaptations enhance the effectiveness of the immune system. ${ }^{5}$ In a time when vaccination for SARS-CoV-2 infection is unavailable one feasible alternate option is to increase the effectiveness of the immune system. ${ }^{6}$

Stressing the importance of physical activity, especially during the COVID-19 pandemic, WHO re-emphasized guidelines of global recommendations on physical activity for health specifying time duration for doing various kinds of physical activities by different age groups (6-65 yrs). According to the recommendation adults of age group 18-64 should do at least 150 minutes of moderate-intensity physical activity throughout the week, or do at least 75 minutes of vigorous-intensity physical activity throughout the week, or an equivalent combination of moderate- and vigorous-intensity activity. For additional health benefits, adults should increase their moderate-intensity physical activity to 300 min per week, or equivalent. Muscle-strengthening activities should be done involving major muscle groups on 2 or more days a week. ${ }^{7}$ During the pre COVID times, WHO found that globally, 1 in 4 adults is not active enough. ${ }^{8}$ Various studies ${ }^{9-11}$ have shown that at least $60 \%$ immigrant South Asians of Canada, UK and US are comparatively inactive than the native white population. While in South Asia itself more than $75 \%$ respondents were found inactive in their leisure time. ${ }^{12}$ Even in India in a study conducted by Indian Council of Medical Research-India Diabetes ${ }^{13}$ it was found that more than $50 \%$ respondents were inactive while $31.9 \%$ were active and only $13.7 \%$ were highly active. In a study conducted by Kantar IMRB (2018) it was found that in the last one year one third of the respondents had not done any physical activity and also that they considered lack of time as the major constraint for the same. ${ }^{14}$ Several studies ${ }^{6,15-17}$ have supported the theory that physical activity boosts our immune system, so it becomes imperative to study the physical activity behaviour of people especially during such a pandemic. Although several studies have been conducted with respect to lockdown and its impact on mental health, physical health has not been a much discussed issue in Indian context. In order to fill that gap this study is an attempt to study the physical activity behaviour of people and various factors affecting it during this pandemic. Objectives of the study were to study the physical activity behaviour, levels and its relationship with personal variables during COVID-19 lockdown, and to explore the differences between the inactive and active group respondents in terms of physical activity preferences, motivating and restricting factors.

\section{MATERIALS AND METHODS}

Sample and design: Cross sectional descriptive online survey design was used in the study. Data was collected using Google forms. Snowball sampling method was used to reach the respondents as both the researchers of this study circulated the questionnaire through their social media platforms (Whatsapp, Facebook, Emails, etc) requesting everyone to circulate it further. While selecting the responses for analysis age of the respondents (above 18 yrs) their literacy level (middle school and above) and nationality (Indian) were considered. Considering these three criteria out of 434 responses 400 responses were finally selected for analysis.
Measures: The survey link was circulated between $1^{\text {st }}$ June 2020 and $30^{\text {th }}$ June 2020. It consisted of four parts; 1) Demographics, 2) Occupation, Screen and Sleep behaviour, 3) Physical Activity behaviour, 4) Preferred physical activities, restricting and motivating factors to do any physical activity.

Physical activity: Physical activity is defined as any bodily movement produced by skeletal muscles that require energy expenditure. Popular ways to be active are through walking, cycling, sports and recreation, and can be done at any level of skill and for enjoyment (WHO, 2018).

All the physical activities were self reported by the respondents and to calculate the total physical activity (TPA) self reported occupational physical activity (OPA), household physical activity (HHPA) and leisure time physical activity (LTPA) were considered. Total physical activity (TPA) minutes were calculated as sum of OPA \{Moderate/2*vigorous OPA min/week\}, MV-LTPA \{moderate physical activities min/week+ $2^{*}$ (vigorous physical activities) $\mathrm{min} /$ week $\}$ and household physical activities $\mathrm{min} /$ week.

OPA was measured by questioning respondents about their occupational physical activity type i.e sedentary (mostly sitting)/light (sit and stand)/ moderate (mostly walking)/vigorous (carrying heavy loads) during COVID 19 lockdown and if they were involved in moderate/vigorous OPA then its duration in minutes/week was asked. LTPA was measured by questioning respondents about their involvement, in minutes per week, in moderate physical activities such as yoga, dance, brisk walk, bicycling, games etc. and also in vigorous physical activities such as weight training, aerobic exercise, running/jogging etc. HHPA was measured by questioning respondents about their involvement, minutes per week, in household chores such as mopping/sweeping/cleaning/ cooking etc.

Respondents who reported TPA for less than $150 \mathrm{~min} /$ week were considered to be inactive. Similarly, people who reported at least 150 $\mathrm{min}$ /week of TPA were considered to be active. Active category was further categorized into two parts i) moderately active, performing TPA for 150-300 $\mathrm{min} /$ week, ii) very active, performing TPA for $>300 \mathrm{~min} /$ week.

\section{Statistical analysis}

Descriptive information including demographic characteristics of the respondents, occupational, screen time and sleep behaviour during COVID-19 lockdown, physical activity levels (inactive, moderately active, very active) in different domains were summarized and split by sex only, whereas BMI and physical activity behaviour of the respondents were split by sex and physical activity level. Data was reported as means \pm SD for continuous variables and as frequency and percentages for categorical variables. Independent sample t test/one way ANOVA and chi square test were used to assess the difference between male and female respondents for both continuous and categorical variables. Preference of leisure time physical activities (LTPA) and motivating and restricting factors in doing physical activity were analysed and on this basis the respondents were split into active ( $>150 \mathrm{~min} /$ week) and inactive ( $<150 \mathrm{~min} /$ week) groups. Comparative analysis was done using chi square tests and frequency and percentages were calculated to see differences between active and inactive groups. All statistical tests were performed using IBM SPSS Statistics 21 and significance was set at $p<0.05$.

\section{RESULTS}

The result has been discussed under four categories: 1) Demographics, 2) Occupation, Screen and Sleep behaviour, 3) Physical Activity behaviour, 4) Preferred physical activities, restricting and motivating factors to do any physical activity. Each category deals with a different aspect of this study. 


\section{Demographics}

A total of 400 respondents (male 56.2\%, female 43.2\%) were selected for the analysis. Majority of the respondents (93.6\%) were between the age group of 18-38 years (mean age $28.4 \pm 7.3$ ) and were unmarried (67.2\%) with education level of graduation and above (91.5\%). Most of the respondents (87.2\%) were Hindu. Majority of the respondents were involved in light occupation $(52.8 \%)$ followed by sedentary occupation (42.5\%) while only $4.2 \%$ were involved in moderate occupation. ${ }^{18}$ In order to categorize the location of the respondents all the Indian states were divided into five zones viz. North, South, East, West and Central. It was found that half of the respondents were from the Northern zone (49.8\%) followed by eastern (28.9\%) and few were from Southern (8.7\%), Western (8.5\%) and Central zone (4.8\%). Age, occupation and religion were significantly associated with sex $(p<0.05)$ whereas education, monthly family income, marital status and location were independent of $\operatorname{sex}(p>0.05)$.

\section{Occupation, Screen and Sleep behaviour}

Table 1 summarizes the occupational, screen and sleep time behavior of respondents, during the COVID19 lockdown, split by sex. Among the working respondents $(n=309)$, a significant difference was found between male $(n=178)$ and female $(n=131)$ in their mode of working as well as in their OPA during COVID 19 lockdown. Out of working respondents half of them were working from home, $25 \%$ were working with following social distancing norms and only $15 \%$ were working as before. During COVID 19 lockdown sedentary behavior in occupation was doubled (80\%) as compared to the pre COVID situation (42.5\% from Table 1 ). While working from home $30 \%$ of the working respondents took not so frequent breaks and most of them were female (43.1\% vs. $19.8 \%)$. Average total screen time was $9.2 \pm 3.6$ hours/day work related average screen time was $5.9 \pm 3.4 \mathrm{hr} /$ day and recreational average screen time was $3.4 \pm 3.5$ hours/day. An increase in screen time, during the lockdown, was mentioned by majority of the respondents $(53.5 \%)$ and this increase was slightly more in female respondents $(58.4 \%)$ than in male respondents (49.8\%). Sleeping hours of $\sim 40 \%$ respondents had increased during the lockdown while it remained the same for $45.8 \%$ and decreased for $\sim 15 \%$ of the respondents. There was no significant difference found between male and female respondents in terms of their sleeping hours, total screen time or change in screen time.

\section{Physical Activity behaviour}

Table 2 shows the physical activity levels in three domains i.e. OPA, MV-LTPA and HHPA as well as its total, all split by sex. During COVID-19 lockdown only 3.3\% (Table 1 ) respondents were involved in moderate OPA that too for $<150 \mathrm{~min} /$ week. Total Physical activity score was independent of sex whereas OPA, MV-LTPA and HHPA were having significant association with sex. Majority of the respondents were doing OPA (100\%), MV-LTPA (58\%) and HHPA (80\%) for $<150$ $\mathrm{min} /$ week and thus were called inactive in respective domains. In the present study, on considering domain-wise, more male respondents (51\%) were participating in MV-LTPA for $>150 \mathrm{~min} /$ week than female respondents (30\%) whereas the case was reversed for HHPA. In terms of TPA almost $1 / 3^{\text {rd }}$ of the respondents were in each group (Inactive $34 \%$, MA 33.5\%, vs 32.5\%). However, the percentage of male respondents was slightly higher in the very active group (>300 min/week).

Table 3 shows BMI, perceived body weight and physical activity behavior of the respondents split by sex and physical activity level. Physical activity level has been categorized as Inactive, Moderately Active and Very Active. Although no significant difference was seen in the physical activity levels in terms of BMI and perceived body weight there was a significant difference in BMI and perceived body weight of male and female respondents.

\begin{tabular}{|c|c|c|c|c|}
\hline Factors & Total & Male & Female & $p$-Value \\
\hline \multicolumn{5}{|c|}{ Current working situation } \\
\hline Not Working & $91(22.8)$ & 49 (21.6) & $42(24.3)$ & \\
\hline Working & $309(77.2)$ & $178(57.6)$ & $131(42.4)$ & $<.001^{*}$ \\
\hline Working as before & $46(15)$ & $26(14.6)$ & $20(15.3)$ & \\
\hline Working from home & $156(50)$ & $91(51)$ & $65(49.6)$ & \\
\hline $\begin{array}{l}\text { Working with following } \\
\text { social distancing norms }\end{array}$ & $77(25)$ & $55(31)$ & $22(16.8)$ & \\
\hline Household Chores & $30(10)$ & $6(3.4)$ & $24(18.3)$ & \\
\hline \multicolumn{5}{|c|}{ Occupational PA during COVID } \\
\hline Sedentary & $324(81)$ & $183(80.6)$ & $141(81.5)$ & $<.001^{*}$ \\
\hline Light & $63(15.7)$ & $33(14.5)$ & $30(17.3)$ & \\
\hline Moderate & $13(3.3)$ & $11(4.8)$ & $2(1.2)$ & \\
\hline \multicolumn{5}{|c|}{ Frequency of breaks while working from home } \\
\hline Total & 156 & 91 & 65 & \\
\hline Every $30 \mathrm{~min}$ & $17(10.9)$ & $11(12)$ & $6(9.2)$ & .047 \\
\hline Every hour & $38(24.4)$ & $23(25.3)$ & $15(23)$ & \\
\hline Every 2 hour & $40(25.6)$ & $29(40)$ & $11(17)$ & \\
\hline Every 4 hour & $7(4.5)$ & $5(5.5)$ & $2(3.1)$ & \\
\hline Not so frequent & $46(29.5)$ & $18(19.8)$ & $28(43.1)$ & \\
\hline Not applicable & $8(5.1)$ & $5(5.5)$ & $3(4.6)$ & \\
\hline $\begin{array}{l}\text { Work related screen } \\
\text { time }(0-16)\end{array}$ & $5.9+3.4$ & $6.2+3.4$ & $5.6+3.4$ & $.079^{\wedge}$ \\
\hline 0 & $24(6)$ & $13(5.7)$ & $11(6.3)$ & \\
\hline $1-4$ & $119(29.8)$ & $60(26.4)$ & $59(34.1)$ & \\
\hline $5-8$ & $169(42.2)$ & $98(43.2)$ & $71(41.0)$ & \\
\hline $9-12$ & $82(20.5)$ & $54(23.8)$ & $28(16.2)$ & \\
\hline$>12$ & $6(1.5)$ & $2(0.9)$ & $4(2.3)$ & \\
\hline $\begin{array}{l}\text { Recreational screen time } \\
(0-16)\end{array}$ & $3.4+3.5$ & $3.2+2.3$ & $3.6+2.3$ & $.114^{\wedge}$ \\
\hline 0 & $8(2)$ & $5(2.2)$ & $3(1.7)$ & \\
\hline $1-4$ & $302(75.5)$ & $182(80.2)$ & $120(69.4)$ & \\
\hline $5-8$ & $74(18.5)$ & $33(14.5)$ & $41(23.7)$ & \\
\hline $9-12$ & $12(3)$ & $5(2.2)$ & $7(4.0)$ & \\
\hline$>12$ & $4(1)$ & $2(0.9)$ & $2(1.1)$ & \\
\hline Total screen time $(0-18)$ & $9.2+3.6$ & $9.3+3.6$ & $9.1+3.6$ & $.565^{\wedge}$ \\
\hline $0-4$ & $42(10.5)$ & $24(10.6)$ & $18(10.4)$ & \\
\hline $5-8$ & $136(34)$ & $69(30.4)$ & $67(38.7)$ & \\
\hline $9-12$ & $147(36.8)$ & $94(41.4)$ & $53(30.6)$ & \\
\hline$>12$ & $75(18.8)$ & $40(17.6)$ & $35(20.2)$ & \\
\hline \multicolumn{5}{|c|}{ Change in screen time } \\
\hline Increased & $214(53.5)$ & $113(49.8)$ & $101(58.4)$ & .071 \\
\hline Decreased & $40(10)$ & $28(12.3)$ & $12(7)$ & \\
\hline Remained same & $146(36.5)$ & $86(37.9)$ & $60(34.6)$ & \\
\hline \multicolumn{5}{|c|}{ Sleeping hours during Covid } \\
\hline Increased & $158(39.5)$ & $87(38.3)$ & $71(41.0)$ & .258 \\
\hline Decreased & $59(14.8)$ & $29(12.8)$ & $30(17.3)$ & \\
\hline Remained Same & $183(45.8)$ & $111(48.9)$ & $72(41.6)$ & \\
\hline
\end{tabular}

The $p$-values represent chi-square tests of independence indicating associations between sex and categorical variables,

$\wedge t$ test was computed for various screen time variable, unit for screen time was hours/day

${ }^{*}$ represents significant association/difference between categorical variables and $\operatorname{sex}$ 
Sijwali and Chauhan.: A Study of Physical Activity Behaviour during the COVID-19 Pandemic

\begin{tabular}{|c|c|c|c|c|}
\hline \multirow[b]{2}{*}{ Domain/ Activity levels } & \multirow{2}{*}{$\begin{array}{c}\text { Inactive } \\
\text { IA }(<150) \\
\mathrm{N}(\%)\end{array}$} & \multicolumn{2}{|c|}{ Active } & \multirow[b]{2}{*}{$p$-Value } \\
\hline & & $\begin{array}{c}\text { MA (150- } \\
300) \\
\text { N (\%) }\end{array}$ & $\begin{array}{c}\text { VA }(>300) \\
\mathrm{N}(\%)\end{array}$ & \\
\hline OPA (400) & $400(100)$ & 0 & 0 & $<.001^{\star}$ \\
\hline Male (227) & 227 & 0 & 0 & \\
\hline Female (173) & 113 & 0 & 0 & \\
\hline MV-LTPA (400) & $232(58)$ & $103(25.8)$ & $65(16.2)$ & $<.001^{*}$ \\
\hline Male (227) & $111(48.9)$ & $63(27.8)$ & $53(23.3)$ & \\
\hline Female (173) & $121(70.0)$ & $40(23.1)$ & $12(6.9)$ & \\
\hline HHPA (400) & $320(80)$ & $72(18)$ & $8(2)$ & $<.001^{*}$ \\
\hline Male(227) & $193(85.0)$ & $31(13.6)$ & $3(1.3)$ & \\
\hline Female (173) & $127(73.4)$ & $41(23.7)$ & $5(3)$ & \\
\hline $\begin{array}{l}\text { TPA (OPA+MV- } \\
\text { LTPA+HHPA) }\end{array}$ & $136(34)$ & $134(33.5)$ & $130(32.5)$ & .078 \\
\hline Male (227) & $70(30.8)$ & $73(32.2)$ & $84(37.0)$ & \\
\hline Female (173) & $66(38.1)$ & $61(35.3)$ & $46(26.6)$ & \\
\hline
\end{tabular}

*The $p$-values represent chi-square tests of independence indicating associations between sex and categorical variables

Higher percentage of female respondents perceived themselves as overweight than they actually were $(41 \%$ vs $22.5 \%)$ whereas a lesser number of male perceived themselves as overweight than they actually were $(26 \%$ vs. $34.4 \%)$. However, more number of male perceived themselves as underweight than they actually were (7.5\% vs $2.6 \%)$ while lesser females perceived themselves as underweight than they actually were $(9.2 \%$ vs $15.6 \%)$ as per their BMI. No significant difference was seen either between male and female respondents or physical activity levels in terms of change in leisure time physical activity (LTPA) and with whom they were staying. Increase in LTPA was seen sex-wise as well as across the groups i.e. inactive, moderately active, and very active. Highest increase in LTPA was among the respondents of the very active group (56.9\%) followed by moderately active group (48.5\%) and lowest increase (39\%) among the respondents of inactive group. In terms of considering the benefits of physical activities sex-wise no significant difference was seen whereas, significant difference was seen among the groups (IA, MA, VA) for the same. Higher percentage of active group respondents (65\% MA, 68.5\% VA) considered PA as beneficial (very to extremely) than inactive group respondents (41.2\%). Sex-wise no significant difference was seen in terms of changing their physical activity behavior in post lockdown times whereas physical activity level wise a significant difference was seen. Physical activity level wise, more than $50 \%$ respondents of each group tend to increase their PA in post COVID lockdown times. Sex-wise as well as physical activity level wise a significant difference was seen in type of physical activity that the respondents were doing. More male (33.5\%) than female (19.6\%) respondents accepted doing moderate to vigorous physical activity (MVPA). It was found that the majority of the active group respondents (MA 55.2\%, VA $44.6 \%)$ preferred moderate physical activity whereas majority of inactive group respondents (44.8\%) preferred light physical activity.

\section{Preferred physical activities, restricting and motivating factors to do any physical activity}

Frequency and percentage of various physical activities done by the respondents of active ( $>150 \mathrm{~min} /$ week) and inactive group $(<150 \mathrm{~min} /$ week) was calculated and a significant difference among them was found $(p<0.05)$. Percentage-wise participation in all the physical activities (yoga, dance, brisk walking, playing games, bicycling, weight training, aerobic exercise, running/jogging, household work) was higher for the active group respondents $(73.1,28,82.2,35.2,20.5,35.2,66.7,58.7,78.4)$ as compared to the inactive group respondents $(52.2,20.6,58.8,17.6$, $8.1,4.4,33.8,17.6,63.5)$. It is concluded that household work and brisk walk were the top two activities done by both the groups whereas weight training for inactive group (4.4\%) and bicycling for active group (20.5\%) respondents was reported as the least preferred physical activity.

The motivating (family and friends, online community and videos, health benefits, more free time, government initiatives, nothing and normal routine) and restricting (nothing, COVID 19 social distancing restrictions, lack of motivation/interest, lack of equipment/space/ instructor and time constraint) factors in doing physical activity were also studied. Family/friends (34.8\%) and health benefits (33.3\%) followed by their normal routine $(29.8 \%)$ acted as motivating factors for the respondents to be physically active. Overall $(3.8 \%)$ as well as across the groups (Inactive $4.4 \%$, active $3.4 \%$ ) government initiative was reported as the least motivating factor. In terms of motivating factor in doing physical activity a significant difference was found between the active and inactive group $(p<0.05)$. Although family/friends was one of the common motivating factors in both the groups (almost 35\%), health benefits played an important role for active group respondents $(38.6 \%)$ as compared to the inactive group (22.8\%). In the active group majority of respondents (93.2\%) were motivated by one or other factor to take up any physical activity whereas in the inactive group nothing could motivate its $19.1 \%$ of respondents to take up any physical activity during this lockdown.

It was found that $30 \%$ of the total respondents reported nothing as the restricting factor in doing physical activity during COVID 19 lockdown. Of the remaining respondents (70\%) most of them (33.3\%) reported COVID 19 social distancing restriction followed by lack of motivation/ interest $(29.7 \%)$ as the barriers in doing any physical activity. Higher percentage of inactive respondents $(34.6 \%)$ than active respondents (13.6\%) pointed out COVID 19 social distancing restrictions as a barrier in being physically active. However, lack of motivation had almost equal percentage $(\sim 12 \%)$ of the respondents in both the groups. There was a significant difference in the active and inactive group's respondents in terms of restricting factors $(p<0.05)$.

\section{DISCUSSION}

In the present study majority of the respondents were young adults (18-38 yrs). All the respondents were literate and their occupational behaviour varied from sedentary to light. As 75\% of the working respondents were working from home their occupational sedentary behaviour has increased, posing a threat to their health. Not only this, increased screen time and sleeping hours along with not so frequent breaks during work has been found leading to an increase in sedentary behaviour which is directly related to various musculoskeletal disorders. ${ }^{19}$ In the present study only $10.9 \%$ of the respondents took a break every $30 \mathrm{~min}$ in compliance with WHO guidelines. Similar results were found in the study conducted in Italy as only $\sim 10 \%$ of the working respondents took a break every $30 \mathrm{~min}$ in compliance with WHO guidelines..$^{20}$ It was found that during COVID-19 lockdown sedentary behaviour in occupation was doubled (80\%, Table 1 ) as compared to pre COVID situation (42.5\%). This is an alarming result as studies have shown that lack of OPA can be associated with increase in obesity, larger waist and hip circumference; and poor performance in most of the fitness test. ${ }^{21}$ Similar results were found in the Hong Kong study where both the sedentary behaviour and sleep duration increased significantly during COVID 19. ${ }^{22}$ Majority of the respondents were doing OPA (100\%), MV-LTPA (58\%) and HHPA 


\begin{tabular}{|c|c|c|c|c|c|c|c|}
\hline & $\begin{array}{l}\text { Male } \\
\text { N (\%) }\end{array}$ & $\begin{array}{l}\text { Female } \\
\mathrm{N}(\%)\end{array}$ & $p$-Value & $\begin{array}{c}\text { IA } \\
(<150) \\
N(\%)\end{array}$ & $\begin{array}{c}\text { MA (150-300) } \\
\text { N (\%) }\end{array}$ & $\begin{array}{c}\text { VA (>300) } \\
\text { N (\%) }\end{array}$ & $p$-Value \\
\hline Total & $227(56.7)$ & $173(43.3)$ & & $134(33.5)$ & $136(34)$ & $130(32.5)$ & \\
\hline$\wedge \mathrm{BMI}$ & $24.5+3.9$ & $22.4+3.6$ & $<.001^{*}$ & $23.5+3.7$ & $23.9+4.8$ & $23.3+3.2$ & .551 \\
\hline Underweight $(<18.5)$ & $6(2.6)$ & $27(15.6)$ & & $8(5.9)$ & $14(10.4)$ & $11(8.5)$ & \\
\hline Overweight (>25) & $78(34.4)$ & $39(22.5)$ & & $38(30)$ & $47(35.1)$ & $32(24.6)$ & \\
\hline \multicolumn{8}{|c|}{ Body weight perception } \\
\hline Underweight & $17(7.5)$ & $16(9.2)$ & $.003^{*}$ & $11(8.1)$ & $9(6.7)$ & $13(10)$ & .120 \\
\hline Normal & $151(66.5)$ & $86(49.7)$ & & $78(57.4)$ & $73(54.5)$ & $86(66.2)$ & \\
\hline Decreased & $68(30)$ & $49(28.3)$ & & $47(34.5)$ & $41(30.6)$ & $29(22.3)$ & \\
\hline No change & $59(26)$ & $32(18.5)$ & & $36(26.5)$ & $28(20.9)$ & $27(20.7)$ & \\
\hline \multicolumn{8}{|c|}{ PA beneficial } \\
\hline Not beneficial & $29(12.8)$ & $27(15.6)$ & .564 & $35(25.7)$ & $8(6)$ & $13(10)$ & $<.001^{*}$ \\
\hline Slightly beneficial & $59(26)$ & $52(30.1)$ & & $45(33.1)$ & $38(28.3)$ & $28(21.5)$ & \\
\hline Very beneficial & $86(37.9)$ & $60(34.7)$ & & $40(29.4)$ & $56(41.8)$ & $50(38.5)$ & \\
\hline Extremely beneficial & $53(23.3)$ & $34(19.6)$ & & $16(11.8)$ & $32(23.9)$ & $39(30)$ & \\
\hline \multicolumn{8}{|c|}{ Change in post COVID PA } \\
\hline Will increase & $139(61.2)$ & $97(56.1)$ & .327 & $86(63.2)$ & $82(61.2)$ & $68(52.3)$ & $<.001^{*}$ \\
\hline MVPA110 & $76(33.5)$ & $34(19.6)$ & & $25(18.4)$ & $29(21.6)$ & $56(43.1)$ & \\
\hline \multicolumn{8}{|c|}{ Staying with } \\
\hline Family & $175(77.1)$ & $143(82.6)$ & .127 & $112(82.4)$ & $102(76.1)$ & $104(80)$ & .486 \\
\hline Friends & $17(7.5)$ & $15(8.7)$ & & $12(8.8)$ & $12(8.9)$ & $8(6.1)$ & \\
\hline Alone & $35(15.4)$ & $15(8.7)$ & & $12(8.8)$ & $20(14.9)$ & $18(13.8)$ & \\
\hline
\end{tabular}

The $p$-values represent chi-square tests of independence indicating associations between sex and categorical variables, and physical activity levels and categorical variables

$\wedge$ BMI p values: $t$ test was used when split by sex and ANOVA was used when split by physical activity levels

${ }^{\star}$ represents significant association/difference between categorical variables and sex and physical activity levels

(80\%) for $<150 \mathrm{~min} /$ week and thus were called inactive in respective domains. Earlier studies have shown that among the various domains of physical activity, involvement of people was highest in the occupational physical activity (OPA). ${ }^{13}$ Particularly in developing countries, occupation and transportation activities represent a substantial proportion of an individual's total physical activity. ${ }^{23}$ But in the present study occupational physical activity and travel is almost negligible and it can't be denied that COVID-19 restrictions might be the reason for it. In the ICMR-INDIAB ${ }^{13}$ study it was found that respondents, who were involved in recreational physical activities (6.2\%), were spending less than $20 \mathrm{~min}$ /day for the same. Results of present study clearly shows that active involvement of both male and female in the MV-LTPA is low but in comparison to female respondent's male respondents are more active in doing MV-LTPA. Several studies ${ }^{10,13,24}$ found similar results which concluded that male were more physically active than females. More female respondents were involved in HHPA for $>150 \mathrm{~min} /$ week than male respondents. Lockdown restrictions might be one of the reasons for low OPA and MVLTPA so people should indulge themselves more in HHPA to compensate for the loss of physical activity in other two domains. Although $66 \%$ respondents of the present study were achieving the goals set by WHO in terms of PA but only $1 / 3^{\text {rd }}$ of them will reap its health benefits as only they are doing it for $>300 \mathrm{~min} /$ week. In the World Health Survey, conducted almost a decade ago, only $17.7 \%$ respondents (19.8\% female and $15.2 \%$ male) were found inactive. ${ }^{12}$ While in a study conducted worldwide in 
2012 it was found that $31.1 \%$ of adults were physically inactive. In India $<19.9 \%$ respondents were found to be inactive. ${ }^{25}$ In light of these studies it can be said that inactivity among people has increased over the time.

When body- weight perception was explored it was found that females perceived themselves as overweight even when they were normal as per their BMI whereas this situation was totally reversed for male. This behaviour can be seen among people irrespective of their age group as was seen among adolescent respondents in the study conducted in Thailand. ${ }^{24}$ In present study no significant association was found between respondents BMI as well as perceived body weight to their physical activity level. Almost half of the respondents reported an increase in their LTPA during the COVID-19 lockdown but no significant difference was found between male, female and their physical activity levels in terms of change in their LTPA. This finding is in contradiction to the study conducted in Hong Kong in which majority of the respondents (72.3\%) mentioned decrease in their LTPA and only $16.5 \%$ mention increase in their LTPA ${ }^{21}$ Whereas Similar results were seen in the Canadian study where physical activities increased more among the active respondents ( $40.3 \%$ vs. $33 \%)$ and decreased more among the inactive respondents ( $40.5 \%$ vs.22.4\%). ${ }^{10}$ Majority of the respondents tend to increase their LTPA in post COVID-19 times and this percentage was high for the inactive group and male respondents. Major concern drawn from these results is that $20 \%$ of the inactive respondents tend to continue with their physical activity for $<150 \mathrm{~min} /$ week which yields no health benefit. Higher percentage of active group respondents (65\% MA, $68.5 \% \mathrm{VA}$ ) considered PA as beneficial (very to extremely) than inactive group respondents (41.2\%). However attention needs to be focused on that $25 \%$ of inactive respondents who consider physical activity not beneficial at all. Despite the fact that most of the respondents considered PA to be beneficial their involvement in MV-LTPA is quite low and involvement of females in MV-LTPA is even lower than male. Unawareness of benefits of physical activity might be one of the reasons for considering it not beneficial at all and that's why efforts should be made to make people more and more aware about the benefits of physical activity. Both sex wise and physical activity level wise significant difference was found in the self reported type of physical activity. Majority of inactive respondents were involved in self reported light physical activity whereas majority of active respondents were involved in self reported moderate physical activity.

On analyzing the type of physical activity done by the respondents it was found that household work and brisk walk were the top two activities done by both the active and inactive respondents. Walking was also the common physical activity for active and inactive groups among the Canadian respondents and participants of inactive groups were more involved in walking (57.2\%) than the active group (19.7\%). ${ }^{10}$ It was family/friends and health benefits that motivated the respondents of present study to involve in physical activity. It was social distancing norms and lack of motivation that acted as a barrier for respondents in doing physical activity. Similar results i.e. lack of motivation and lack of time were reported as the two most common barriers in doing physical activity by the adults of Barranquilla, Colombia. ${ }^{20}$

\section{CONCLUSION}

It can be concluded that physical activity among people was low even before the COVID-19 pandemic, this pandemic acted as a catalyst in promoting sedentary behaviour. Both the sexes are ignoring their physical health but this ignorance is higher among females. They need to be made aware about the benefits of physical health which will act as an intrinsic motivation. Government needs to intervene extensively in promoting physical health especially in times of such pandemic which will have long lasting effects on behaviour of people. As we can see that as far as possible work from home culture is being promoted due to this pandemic. In such scenarios the onus of keeping themselves physically active lies mostly with the people. Those who are not following the guidelines of WHO on physical activity needs to take it seriously and should involve themselves in LTPA at least as per the norms. People need to control their prolonged sedentary behaviour specifically screen time as it will have a long lasting ill-effect on our physical as well as mental health. We have seen studies which reflected that physical health and mental health are intertwined. So, it becomes a prerequisite for people to be physically fit in order to survive during and also after this pandemic.

\section{Ethical Clearance}

The authors declare that the study has been conducted following all the research ethics. Consent of respondents to participate in the study was taken.

\section{CONFLICT OF INTEREST}

The authors declare that they have no conflict interests.

\section{REFERENCES}

1. Rajkumar RP. COVID-19 and mental health: a review of the existing literature. Asian J Psychiatr. 2020 August;52:102066. doi: 10.1016/j.ajp.2020.102066 PMID 32302935.

2. Ministry of Home Affairs, GOI. Guidelines on the measures to be taken by Ministries/Departments of government of India, State/Union Territory Governments and State/Union Territory Authorities for containment of COVID-19 Epidemic in the country. Order N.40-3/2020. 2020. 6 p.

3. ansal I, Hasin F. Of 5 COVID-19 lockdowns in India. 1st phase most effective, shows data, but policy changes have not eased public movement [internet]; 2020. Firstpost [cited Jul 17 2020]. Available from: https://www.firstpost.com/ health/of-5-covid-19-lockdowns-in-india-1 st-phase-most-effective-shows-databut-policy-changes-have-not-eased-public-movement-8434601.html.

4. Siordia JA. Epidemiology and clinical features of COVID-19: a review of current literature. J Clin Virol. 2020 June;127:104357. doi: 10.1016/j.jcv.2020.104357, PMID 32305884.

5. Krüger K, Mooren FC, Pilat C. The immunomodulatory effects of physical activity. Curr Pharm Des. 2016 June;22(24):3730-48. doi: 10.2174/13816128226661603 22145107, PMID 27000826.

6. Sallis JF, Adlakha D, Oyeyemi A, Salvo D. An international physical activity and public health research agenda to inform coronavirus disease-2019 policies and practices. J Sport Health Sci. 2020 May;9(4):328-34. doi: 10.1016/j. jshs.2020.05.005, PMID 32450160

7. World Health Organization. Global recommendations on physical activity for health [Brochure and flyer]. WHO; 2010. Available from: https://www.who.int/ publications/i/item/9789241599979 [cited 20/7/2021].

8. World Health Organization. Physical activity [Factsheet]. WHO; 2020. Available from: https://www.who.int/news-room/fact-sheets/detail/physical-activity [cited 20/7/2021].

9. Williams ED, Stamatakis E, Chandola T, Hamer M. Physical activity behaviour and coronary heart disease mortality among South Asian people in the UK: an observational longitudinal study. Heart. 2011;97(8):655-9. doi: 10.1136/ hrt.2010.201012. PMID 21131381.

10. Bryan SN, Tremblay MS, Pérez CE, Ardern Cl, Katzmarzyk PT. Physical activity and ethnicity: evidence from the Canadian Community Health Survey. Can J Public Health. 2006 July-August;97(4):271-6. doi: 10.1007/BF03405602, PMID 16967744

11. Misra R, Patel TG, Davies D, Russo T. Health promotion behaviors of Gujurati Asian Indian immigrants in the United States. J Immigr Health. 2000;2(4):223-30. doi: 10.1023/A:1009544414050. PMID 16228743.

12. Ranasinghe $C D$, Ranasinghe $P$, Jayawardena $R$, Misra A. Physical activity patterns among South-Asian adults: a systematic review. Int J Behav Nutr Phys Act. 2013 October;10:116. doi: 10.1186/1479-5868-10-116, PMID 24119682

13. Anjana RM, Pradeepa R, Das AK, Deepa M, Bhansali A, Joshi SR, Joshi PP Dhandhania VK, Rao PV, Sudha V, Subashini R, Unnikrishnan R, Madhu SV, KaurT, Mohan V, Shukla DK, ICMR- INDIAB Collaborative Study Group. Physical activity and inactivity patterns in India - results from the ICMR-INDIAB study (Phase-1) [ICMR-INDIAB-5]. Int J Behav Nutr Phys Act. 2014 February;11(1):26. doi: 10.1186/1479-5868-11-26, PMID 24571915.

14. Economic times. Study reveals that $1 / 3$ rd of India hasn't done any physical activity even once in the last 1 year! [internet]; 2018 May 9 [cited 2020 August5]. Available from: https://health.economictimes.indiatimes.com/news/industry/ study-reveals-that-1/3rd-of-india-hasnt-done-any-physical-activity-even-oncein-the-last-1-year/64096632 [cited 20/7/2021]. 
15. World Health Organization. Healthy at home-physical activity [internet] [cited Aug 5 2020]. Available from: https://www.who.int/news-room/campaigns/ connecting-the-world-to-combat-coronavirus/healthyathome/healthyathome-physical-activity.

16. Hardman AE. Physical activity and health: current issues and research needs Int J Epidemiol. 2001 October;30(5):1193-7. doi: 10.1093/ije/30.5.1193, PMID 11689544

17. Chen $P$, Mao L, Nassis GP, Harmer P, Ainsworth BE, Li F. Coronavirus disease (COVID-19): the need to maintain regular physical activity while taking precautions. J Sport Health Sci. 2020 March;9(2):103-4. doi: 10.1016/j.jshs.2020.02.001, PMID 32099716.

18. Church TS, Thomas DM, Tudor-Locke CT, Katzmarzyk PT, Earnest CP, Rodarte RQ, Martin CK, Blair SN, Bouchard C. Trends over 5 decades in US occupationrelated physical activity and their associations with obesity. PLOS ONE. 2011 May;6(5):e19657. doi: 10.1371/journal.pone.0019657, PMID 21647427.

19. Stefánsdóttir R, Gudmundsdottir SL. Sedentary Behavior and musculoskeletal Pain: a five-year longitudinal Icelandic study [Thesis for the degree of Master of Public Health Sciences]. Faculty of Sport, Leisure Studies and Social Education School of Education, University of Iceland. Iceland; 2017 May [cited 2020 August 6]. Available from: https://www.sciencedirect.com/science/article/abs/ pii/S003335061730166X?via\%3Dihub [cited 20/7/2021].

20. Ricci F, Izzicupo P, Moscucci F, Sciomer S, Maffei S, Di Baldassarre A, Mattioli AV
Gallina S. Recommendations for physical inactivity and sedentary behavior during the coronavirus disease (COVID-19) Pandemic. Front Public Health. 2020 May;8:199. doi: 10.3389/fpubh.2020.00199, PMID 32574294.

21. Herazo-Beltrán YH, Pinillos Y, Vidarte J, Crissien E, Suarez D, García R. Predictors of perceived barriers to physical activity in the general adult population: A crosssectional study. Braz J Phys Ther. 2017 January-February:21(1):44-50. doi: 10.1016/j.bjpt.2016.04.003, PMID 28442074.

22. Zheng C, Huang WY, Sheridan S, Sit CHP, Chen XK, Wong SH COVID-19 Pandemic brings a sedentary lifestyle in young adults: A cross-sectional and longitudinal study. Int J Environ Res Public Health. 2020 August;17(17). doi: 10.3390/ijerph17176035, PMID 32825092

23. Hallal PC, Victora CG, Wells JCK, Lima RC. Physical inactivity: prevalence and associated variables in Brazilian adults. Med Sci Sports Exerc. 2003 November [cited 2020 August18];35(11):1894-900. doi: 10.1249/01.MSS.0000093615.33774.0E, PMID 14600556.

24. Sirirassamee T, Phoolsawat S, Limkhunthammo S. Relationship between body weight perception and weight-related behaviours. J Int Med Res. 2018 June;46(9):3796-808. doi: 10.1177/0300060518780138, PMID 29896985.

25. Hallal PC, Andersen LB, Bull FC, Guthold R, Haskell W, Ekelund U, Lance Physical Activity Series Working Group. Global Physical Activity Levels: surveillance progress, pitfalls, and prospects. Lancet. 2012 July;380(9838):247-57. doi: 10.1016/S0140-6736(12)60646-1, PMID 22818937.

Cite this article : Sijwali S, Chauhan A. A Study of Physical Activity Behaviour during the COVID-19 Pandemic. Int J Med Public Health. 2021;11(4):195-201. 